\title{
Air pollution control for occupational health improvement
}

\author{
L. Santarpia, F. Gugliermetti \& G. Zori \\ Department of "Fisica Tecnica", Rome University "La Sapienza", Italy
}

\begin{abstract}
Indoor air pollution can make workplaces worse. Mechanical or natural ventilation systems, impelled by thermal gradients or wind pressure, can reduce indoor pollution levels by introducing adequate indoor air changes; moreover airflows can drag pollutant gases both from the external environment and among internal spaces. An air curtain system can reduce the airflow through openings of adjoining spaces and, as a consequence, can realize a system to control pollution. Flux reduction, gaseous and particulate pollutant control and human exposure time produced by air curtain ventilation systems are investigated by theoretical and advanced CFD analysis in order to improve their design by general guidelines.

Keywords: air curtain, pollution control, free air jet, pollutant flux.
\end{abstract}

\section{Introduction}

Human exposure to particulates has recently received considerable attention as a result of epidemiological studies showing associations between environmental particle concentration and mortality. These associations have been initially demonstrated for total suspended particles (TSP) and $\mathrm{PM}_{10}$; however, results from later studies suggest that fine particles $\left(\mathrm{PM}_{2.5}\right)$ and particle components, such as sulphate $\left(\mathrm{SO}_{4}{ }^{2-}\right)$ and aerosol strong acidity $\left(\mathrm{H}^{+}\right)$, may also be associated with increased mortality and other adverse health impacts.

From studies of indoor environments, it is clear that significant fraction (50-90\%) of outdoor $\mathrm{PM}_{10}, \mathrm{PM}_{2.5}, \mathrm{SO}_{4}{ }^{2-}$ and $\mathrm{H}^{+}$penetrate indoors. Once indoors, these particulate species may be depleted through deposition onto surfaces, or, in the case of $\mathrm{H}^{+}$, through reactions with other indoor pollutants. 
The vehicle emissions are one of most important outdoor PM sources. The pattern of particles concentration is function of the distance from the roads and change around the building envelope; besides street canyon effects, local airflow patterns, reciprocal building locations can largely influence concentration and size particles distributions. Particles emitted from vehicles can penetrate indoors, and the degree to which this occurs depends on the characteristics of the buildings.

The multiplicity of factors involved in the process of penetration of particles produces large variations in the expected outcomes, i.e. in terms of vehicleaffected indoor particle concentration levels. Therefore, various studies, in which particle concentration levels were measured indoor and compared with the outdoor concentrations, have led to different conclusions regarding the extent of vehicle impact. This great spread in results indicates the complexity of the processes involved and thus the need for a good understanding of the specific urban setting in the assessment either of the human exposure or of the risk related to vehicle emission contributions to indoor particle concentration levels.

\section{Background}

A study of indoor and outdoor $\mathrm{PM}_{10}$ and $\mathrm{PM}_{2.5}$ concentrations was carried out in the indoor and outdoor environmental of 28 houses in the area of Huddersfield, England [1], with the objective to identify the effect of road emissions on particle concentrations. The houses were selected both to provide a range of different locations in terms of distance from main roads and to be consistent in their ventilation, internal emission sources, and overall design. The houses within $50 \mathrm{~m}$ from the main road were classified as 'proximity' group, while the others as 'background' group. The mean indoor and outdoor $\mathrm{PM}_{10}$ and $\mathrm{PM}_{2.5}$ concentrations measured for 'proximity' and 'background' houses, with their the median ratios for each couple of 'proximity' and 'background' houses are presented in Tab. 1.

Table 1: $\quad$ Measured concentration at 'proximity' and 'background' houses.

\begin{tabular}{|c|c|c|c|}
\hline Pollutant & Location & $\begin{array}{c}\text { 'Proximity' homes } \\
\left(\mu \mathrm{g} / \mathrm{m}^{3}\right)\end{array}$ & $\begin{array}{c}\text { 'Background' homes } \\
\left(\mu \mathrm{g} / \mathrm{m}^{3}\right)\end{array}$ \\
\hline $\mathrm{PM}_{10}$ & Indoor & 35.36 & 34.91 \\
\hline $\mathrm{PM}_{2.5}$ & Indoor & 17.81 & 19.52 \\
\hline $\mathrm{PM}_{10}$ & Outdoor & 36.25 & 33.70 \\
\hline $\mathrm{PM}_{2.5}$ & Outdoor & 18.91 & 23.31 \\
\hline
\end{tabular}

The decrease in these mass concentrations between the values at the minimum distance from the road and the background levels ranged up to about $25-30 \%$ and was noticeable in the first $20-30 \mathrm{~m}$ from the road. Considering this relatively small gradient, and that many of the 'proximity' houses were already 
at the roadside, little impact of vehicle emissions on indoor $\mathrm{PM}_{10}$ and $\mathrm{PM}_{2.5}$ concentration levels indoor is to be expected.

Time distribution of $\mathrm{PM}_{10}$ concentrations were performed in Hong Kong [2] for two indoor sites located next to main roads; measurements, only for one site, showed two peaks, one at around 7 am and the second at around $5 \mathrm{pm}$, corresponding to the peak-hour traffic on the street. The lowest concentration was measured at about midnight.

A different example is provided by a study conducted by Jamriska et al. 2000 [3] on the fifth floor of an office building located about $100 \mathrm{~m}$ from a busy road. Particles in the range 0.016 to $0.626 \mu \mathrm{m}$ were measured by an SMPS; in this study, the presence of significant indoor pollutant sources was not identified and it was shown that the indoor airborne particles distribution followed outdoor air pattern, in which the vehicle combustion aerosols represented the main pollution source. Fig. 1 compares outdoor particles size distribution with filtered air though a battery of Pyracube deep-bed filters (with an efficiency of approximately $30 \%$ according to classification by the AS1132 No. 1 dust methylene blue test), and with filtered and air conditioned air.

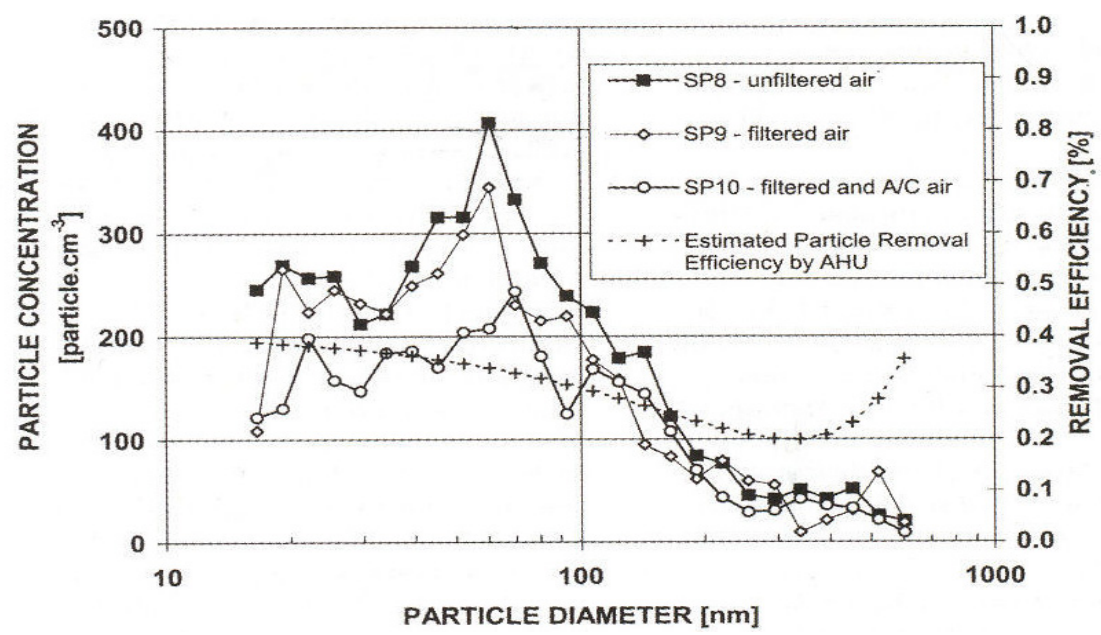

Figure 1: $\quad$ Particles size distribution measured for different ventilation system and particle removal efficiency.

Figure 1 shows similar distributions of particulate sizes for all the considered cases, also if concentrations are lower in filtered and air-conditioned; also the peak of distributions, due to the vehicle emission, is clearly visible in all the indoor distributions.

Studies on air curtain dynamic efficiency, respect both to the improvement of indoor air quality and to reduction of human exposure to hazardous fumes, has been conducted by Santarpia et al. $[4,5,6,7]$ for different geometry and thermo fluid dynamic boundary conditions. 


\section{Experimental methodology}

A 2D meshed (5000 nodes) model has been built (Fig. 2) and an isothermal fluid-dynamic analysis has been carried out for different boundary conditions:

- the outdoor atmosphere $(3 \times 4 \mathrm{~m})$ and the indoor atmosphere $(2.1 \div 10.5 \mathrm{x}$ $4 \mathrm{~m}$ ) constitutes the calculation domain;

- $\quad$ the wall are set adiabatic;

- the doorway allows indoor-outdoor airflows;

- the air curtain is installed on the communicating door;

- the air curtain operates with external filtered air $\left(0.4 \mathrm{~m}^{3} / \mathrm{h} \mathrm{x} \mathrm{m}\right)$;

- a variable height $(0 \div 1.2 \mathrm{~m})$ window is installed on bottom wall.

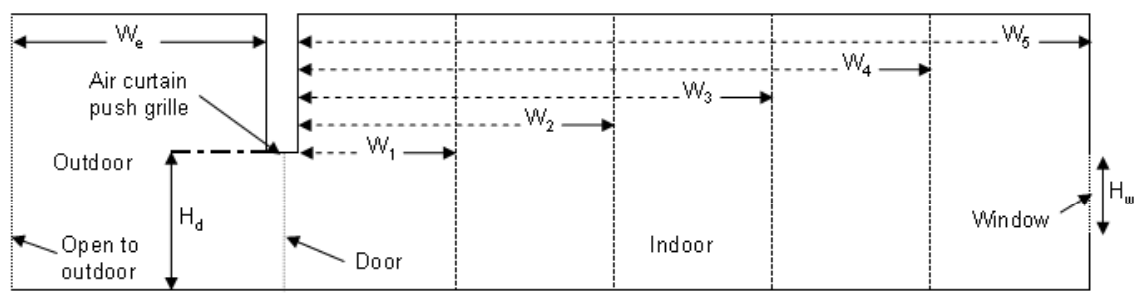

Figure 2: $\quad$ Simulation layout.

A $\mathrm{k}-\varepsilon$ model, implemented in a commercial software (FLUENT), is used to solve the fluid-dynamic field in the calculation domain.

The standard k- $\varepsilon$ model is a semi-empirical model based on model transport equations for the turbulence kinetic energy $(\mathrm{k})$ and its dissipation rate $(\varepsilon)$. In the derivation of the $\mathrm{k}-\varepsilon$ model, it was assumed that the flow is fully turbulent, and the effects of molecular viscosity are negligible. The standard k- $\varepsilon$ model is therefore valid only for fully turbulent flows. The $\mathrm{k}$ and $\varepsilon$ are obtained from the following equations (Einstein notation):

$$
\frac{\partial}{\partial t}(\rho k)+\frac{\partial}{\partial x_{i}}\left(\rho k u_{i}\right)=\frac{\partial}{\partial x_{j}}\left[\left(\mu+\frac{\mu_{t}}{\sigma_{k}}\right) \frac{\partial k}{\partial x_{j}}\right]+S_{k}+S_{b}-\rho \varepsilon-Y_{M}+S^{\prime}
$$

and

$$
\frac{\partial}{\partial t}(\rho \varepsilon)+\frac{\partial}{\partial x_{i}}\left(\rho \varepsilon u_{i}\right)=\frac{\partial}{\partial x_{j}}\left[\left(\mu+\frac{\mu_{t}}{\sigma_{\varepsilon}}\right) \frac{\partial \varepsilon}{\partial x_{j}}\right]+C_{1} \frac{\varepsilon}{k}\left(S_{k}+C_{2} S_{b}\right)-C_{3} \rho \frac{\varepsilon^{2}}{k}+S^{\prime \prime}
$$

In these equations, $S_{k}$ represents the generation of turbulence kinetic energy due to the mean velocity gradients. $S_{b}$ is the generation of turbulence kinetic energy due to buoyancy. YM represents the contribution of the fluctuating 
dilatation in compressible turbulence to the overall dissipation rate. $C_{1}, C_{2}$ and $C_{3}$ are constants. $\sigma_{\mathrm{k}}$ and $\sigma_{\varepsilon}$ are the turbulent Prandtl numbers for $\mathrm{k}$ and $\varepsilon$, respectively. $S^{\prime}$ and $S^{\prime \prime}$ are user-defined source terms. The turbulent (or eddy) viscosity,$\mu_{t}$, is computed by combining $\mathrm{k}$ and $\varepsilon$ as follows:

$$
\mu_{t}=\rho C_{4} \frac{k^{2}}{\varepsilon}
$$

where $C_{4}$ is a constant.

The CFD simulation has been used to esteem the air curtain airflows distribution. In figure 3 the entrained airflows notation is presented.

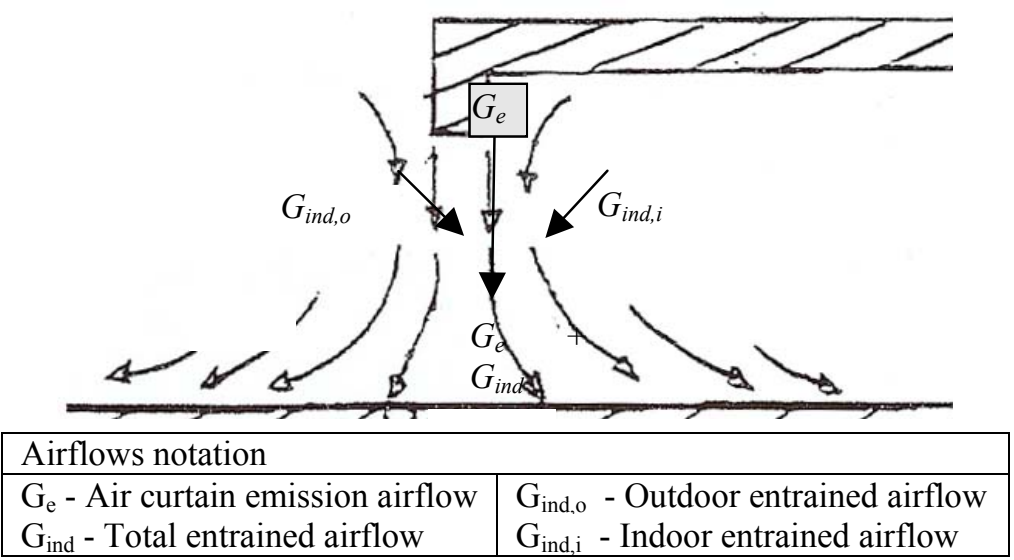

Figure 3: Confined air jet entrained airflows.

The theoretical indoor concentration, $C_{i n}$, can be carried out by the mass balance equation (Fig. 4):

$$
\frac{d\left(V \cdot C_{i n}\right)}{d t}=G_{3} \cdot C_{M}-\left(G_{4}+G_{5}\right) \cdot C_{i n}
$$

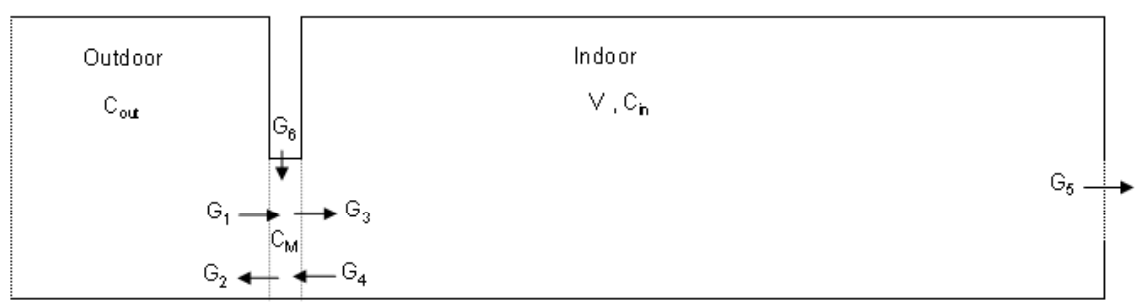

Figure 4: Indoor mass balance notation. 
The $\mathrm{C}_{\mathrm{M}}$ value is carried out assuming a perfect mixing of entrained air:

$$
C_{M}=\frac{G_{1} C_{o u t}+G_{4} C_{\text {in }}+G_{6} C_{e}}{G_{2}+G_{3}}
$$

Integrating and setting $C=C_{0}$ at $t=0$ :

$$
\begin{gathered}
C_{\text {in }}=\left(C_{0}-\frac{K_{2}}{K_{1}}\right) e^{-\frac{K_{1}}{V} t}+\frac{K_{2}}{K_{1}} \\
K_{1}=G_{4}+G_{5}-\frac{G_{3} \cdot G_{4}}{G_{2}+G_{3}} ; K_{2}=G_{3} \frac{G_{1} \cdot C_{\text {out }}+G_{e} \cdot C_{e}}{G_{2}+G_{3}}
\end{gathered}
$$

\section{Results}

Based on CFD numerical data the entrained airflows (Fig. 3) are presented in table 2. In last column is presented the external entrained airflow to total air curtain entrained airflow ratio, $\psi$, as:

\begin{tabular}{|c|c|c|c|c|c|c|c|c|c|c|c|}
\hline $\mathrm{H}_{\mathrm{w}} / \mathrm{H}_{\mathrm{d}}$ & $W / H_{d}$ & $\mathrm{G}_{\text {ind },}$ & $\mathrm{G}_{\text {ind }, \mathrm{i}}$ & $\mathrm{G}_{\text {ind }}$ & $\psi$ & $\mathrm{H}_{\mathrm{w}} / \mathrm{H}_{\mathrm{d}}$ & $\mathrm{W} / \mathrm{H}_{\mathrm{d}}$ & $\mathrm{G}_{\text {ind } \rho}$ & $G_{\text {ind }, i}$ & $G_{\text {ind }}$ & $\psi$ \\
\hline 0.00 & 1 & 0.092 & 0.279 & 0.371 & 0.25 & 0.43 & 1 & 0.101 & 0.114 & 0.215 & 0.47 \\
\hline 0.00 & 2 & 0.092 & 0.274 & 0.366 & 0.25 & 0.43 & 2 & 0.101 & 0.117 & 0.218 & 0.46 \\
\hline 0.00 & 3 & 0.095 & 0.286 & 0.381 & 0.25 & 0.43 & 3 & 0.101 & 0.117 & 0.218 & 0.46 \\
\hline 0.00 & 4 & 0.098 & 0.292 & 0.390 & 0.25 & 0.43 & 4 & 0.102 & 0.119 & 0.220 & 0.46 \\
\hline 0.00 & 5 & 0.100 & 0.294 & 0.393 & 0.25 & 0.43 & 5 & 0.103 & 0.118 & 0.221 & 0.47 \\
\hline 0.14 & 1 & 0.094 & 0.215 & 0.309 & 0.30 & 0.57 & 1 & 0.105 & 0.109 & 0.214 & 0.49 \\
\hline 0.14 & 2 & 0.092 & 0.270 & 0.362 & 0.25 & 0.57 & 2 & 0.108 & 0.108 & 0.216 & 0.50 \\
\hline 0.14 & 3 & 0.095 & 0.286 & 0.381 & 0.25 & 0.57 & 3 & 0.110 & 0.111 & 0.220 & 0.50 \\
\hline 0.14 & 4 & 0.098 & 0.293 & 0.392 & 0.25 & 0.57 & 4 & 0.113 & 0.114 & 0.226 & 0.50 \\
\hline 0.14 & 5 & 0.091 & 0.216 & 0.307 & 0.30 & 0.57 & 5 & 0.122 & 0.115 & 0.237 & 0.52 \\
\hline 0.29 & 1 & 0.098 & 0.118 & 0.215 & 0.39 & \multirow{5}{*}{\multicolumn{6}{|c|}{$\begin{array}{l}\mathrm{H}_{\mathrm{d}}, \mathrm{H}_{\mathrm{w}}-\text { Door and window height }(\mathrm{m}) \\
\mathrm{W}-\mathrm{Indoor} \mathrm{Inace} \text { length }(\mathrm{m}) \\
\mathrm{G}_{\text {ind }}, \mathrm{G}_{\text {ind,o }}, \mathrm{G}_{\text {ind,i }}-\text { Total, outdoor and indoor } \\
\text { entrained airflow }\left(\mathrm{m}^{3} / \mathrm{h} \times \mathrm{m}\right)\end{array}$}} \\
\hline 0.29 & 2 & 0.097 & 0.121 & 0.218 & 0.36 & & & & & & \\
\hline 0.29 & 3 & 0.096 & 0.122 & 0.218 & 0.37 & & & & & & \\
\hline 0.29 & 4 & 0.096 & 0.124 & 0.220 & 0.39 & & & & & & \\
\hline 0.29 & 5 & 0.097 & 0.125 & 0.221 & 0.43 & & & & & & \\
\hline
\end{tabular}

$$
\psi=\frac{G_{i n d, o}}{G_{i n d}} \text {; with } G_{i n d}=G_{i n d, i}+G_{i n d, o} .
$$

Table 2: $\quad$ Entrained airflows.

The indoor volume extension not affect the $\psi$ ratio, instead the indoor natural ventilation through the window have an influence on the entrained airflows 
(fig. 5). The airflows distribution reach the free jet conditions $(\psi=0.5)$ for larger window surface.

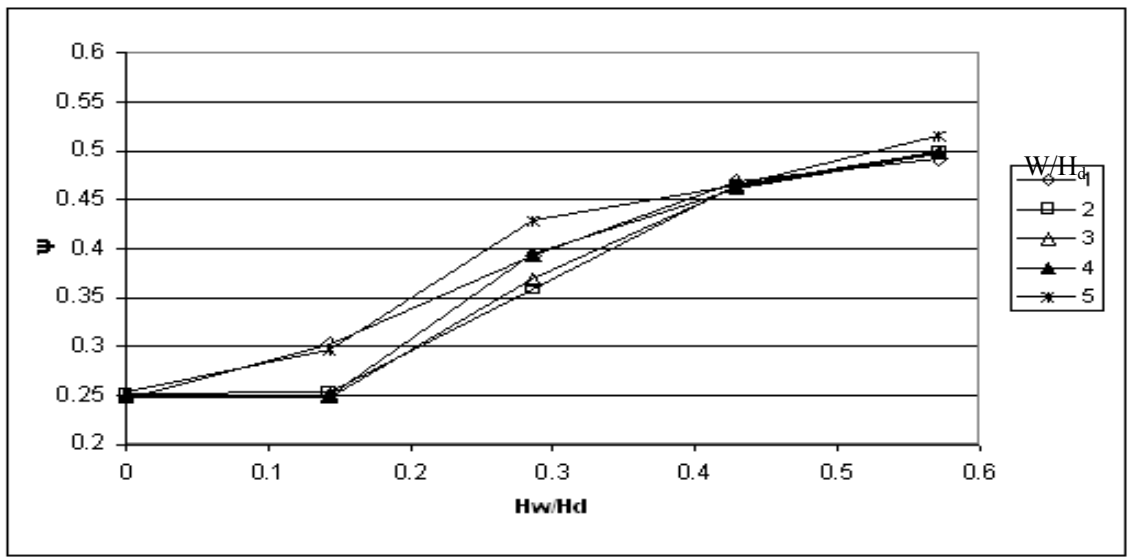

Figure 5: $\quad \Psi$ ratio vs. window height and indoor space length.

The indoor particle concentration as been theoretically carried out using the same model of Fig. 4. The outdoor concentration and the efficiency of the air curtain filter has been derived from Jamriska et al. [3] and are reported in table 3 for each particle diameter.

Table 3: Outdoor particle concentration and filter removal efficiency.

\begin{tabular}{|c|c|c|c|c|c|c|c|c|c|c|c|c|c|c|}
\hline $\mathrm{D}(\mathrm{nm})$ & 20 & 30 & 40 & 50 & 60 & 70 & 80 & 90 & 100 & 200 & 300 & 400 & 500 & 600 \\
\hline $\mathrm{C}_{\text {out }}\left(\mathrm{particle} / \mathrm{cm}^{3}\right)$ & 270 & 210 & 270 & 320 & 400 & 340 & 270 & 250 & 230 & 90 & 50 & 45 & 30 & 20 \\
\hline$\eta(\%)$ & 39 & 38 & 36 & 35 & 34 & 33 & 32 & 31 & 30 & 24 & 20 & 21 & 28 & 36 \\
\hline
\end{tabular}

The particle indoor concentrations vs. particle diameters are presented in Fig. 6. The outlet window airflow not affect the air curtain efficiency for $\mathrm{H}_{w} / \mathrm{H}_{\mathrm{d}}$ ratio lower than 0.15 . The air curtain operates with external filtered air can reduce the indoor particle concentration up to $50 \%$.

\section{Remarks}

During the last two decades, there has been increasing concern over the effects of indoor contamination on health. Changes in building design intended to improve energy efficiency have meant that modern homes are frequently more airtight than older structures. This has led to more comfortable buildings with lower running cost, but has also caused indoor environments in which contaminants may build up to much higher concentrations than before. Indoor air and dust, besides food and workplace, are significant sources of exposure for the general population, especially children. Indoor pollution has been ranked by the United 
States Environmental Protection Agency Advisory Board (EPA) and the Centres for Disease Control (CDC) as a high environmental risk [8].

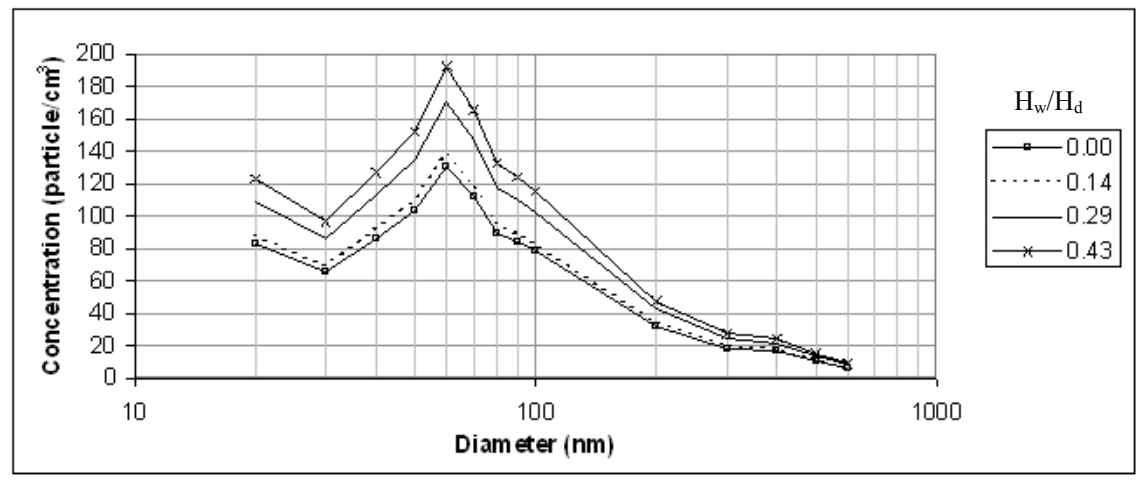

Figure 6: Particle indoor concentration.

Besides outdoor air (vehicle-related emission), smoking has been found to be the most important source of $\mathrm{PM}_{2.5}$ in indoor air, and cooking has been identified as the second strongest source of fine PM in indoor air [9]. As a result of these sources, indoor particle concentrations are often higher than the corresponding outdoor levels. These findings, in conjunction with the fact that people spend the majority of their time indoors, suggest indoor sources to be important contributors to personal exposure to $\mathrm{PM}_{10}$ and $\mathrm{PM}_{2.5}$.

The air curtain system can effectively hinder the outdoor-to-indoor contaminant diffusion and the indoor-to-indoor air exchange between two confined adjoining spaces. The filter pack installed inside the air curtain device have a $31 \%$ average removal efficiency in consequence the indoor diameter distribution of particles is different from outdoor, with variation between $-7 \%$ and $15 \%$ (fig. 7 ).

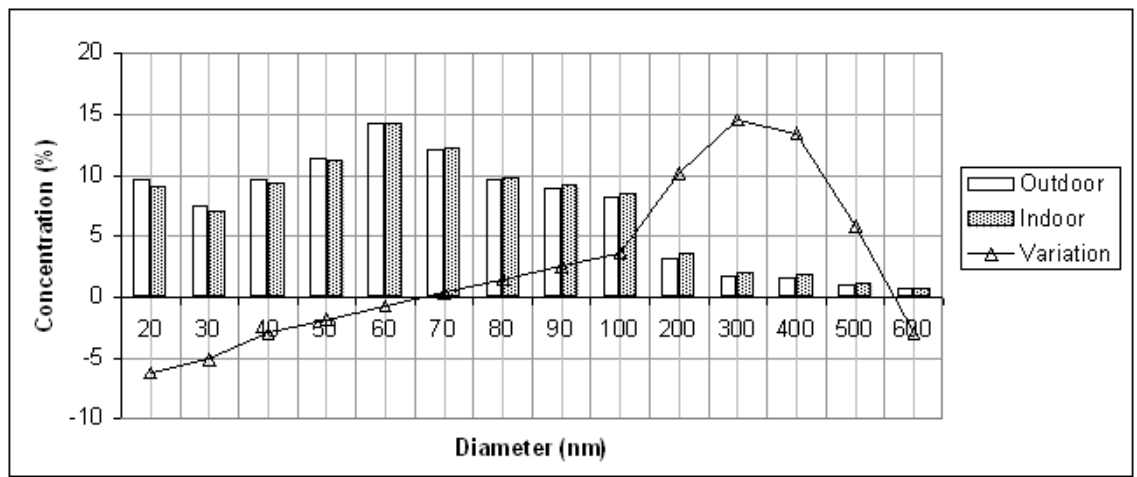

Figure 7: Particle diameter distribution and indoor-outdoor variation. 


\section{Acknowledgement}

This work has been supported with the economical contribute of the "Fondazione Cassa di Risparmio di Roma" in the frame of a national program devoted to the human health protection.

\section{References}

[1] Kingham S., Briggs D., Elliot P., Fischer P., Lebret E., 2000. Spatial variations in the concentrations of traffic-related pollutants in indoor and outdoor air in Huddersfield, England. Atmospheric Environment 34, 905 916.

[2] Chao M.L., Mao I.F., 1998. Spatial variations of airborne particles in metropolitan Taipei. Science of the Total Environment 209, 225-231.

[3] Jamriska M., Morawska L., Clark B., 2000.The effect of ventilation and filtration on submicrometer particles in an indoor environment. Indoor Air 10, 19-26.

[4] Santarpia L., Gugliermetti F., 2002. Smoke movement and management in larges spaces. Heat and Technology (Vol.1). - International Journal of heat and technology.

[5] Santarpia L, Gugliermetti F., 2000. Air curtains to reduce outdoor pollutants infiltration through buildings aperture. Proc of Intren Conf. HB2000, Helsinki, August 5-10.

[6] Santarpia L. Gugliermetti F., 1999. A phenomenological approach to the performance of shutter type air curtains Proc. Of Air pollution 99, 27-29 July, San Francisco.

[7] Santarpia L., Gugliermetti F., Zori G., 2005. Dynamic efficiency of air curtain systems. HEFAT2005, 4th International Conference on Heat Transfer, Fluid Mechanics and Thermodynamics. 19-23 September 2005, Cairo, Egypt.

[8] USEPA (United States Environmental Protection Agency), 2001. Exposure factors handbook Vol III, Chapter 17. Natural Center for Environmental Assessment. Whashington, D.C.

[9] Monn C., Fuchs A., Hogger D., Junker M. Et al. 1997. Particulate matter less than $10 \mu \mathrm{m}\left(\mathrm{PM}_{10}\right)$ and fine particles less than $2.5 \mu \mathrm{m}\left(\mathrm{PM}_{2.5}\right)$ : relationship between indoor, outdoor and personal concentrations. Science of the Total Environment 208, 15-21. 